\title{
PENGARUH ASUHAN SAYANG IBU TERHADAP KONTRAKSI PERSALINAN DAN KECEMASAN IBU DI PUSKESMAS WILAYAH TANGERANG SELATAN
}

\author{
Sri Handayani ${ }^{1}$ \\ ${ }^{1}$ Jurusan kebidanan, Politeknik Kesehatan Kemenkes Jakarta I, Indonesia
}

\begin{tabular}{ll}
\hline Info Artikel & Abstrak \\
\hline Genesis Naskah: & Banyak komplikasi yang menyebabkan kematian ibu dan bayi bisa dihindari jika \\
Submissions: $07-11-$ & persalinan dikelola dengan baik. Semua persalinan harus ditangani oleh tenaga \\
2020 & kesehatan yang terlatih dan kompeten dengan mendiagnosis dan menangani \\
Revised: $18-11-2020$ & komplikasi secara cepat dan akurat. Dalam memberikan asuhan sangat penting \\
Accepted: $19-11-2020$ & $\begin{array}{l}\text { diingat bahwa kemungkinan besar masyarakat akan menggunakan pelayanan yang } \\
\text { baik dengan menerapkan asuhan maternal. Asuhan sayang ibu adalah pengasuhan }\end{array}$ \\
\hline Kata Kunci: & dengan prinsip saling menghormati budaya, kepercayaan dan keinginan ibu. Salah \\
Asuhan sayang ibu, & satu prinsip asuhan sayang pada ibu bersalin adalah melibatkan suami dan keluarga \\
kontraksi persalinan, & selama persalinan. Desain penelitian menggunakan analitik observasional dengan \\
kecemasan & pendekatan case control. Populasi penelitian adalah ibu bersalin yang melahirkan \\
& di puskesmas wilayah Tangerang Selatan pada bulan Juni sampai Oktober 2018. \\
& $\begin{array}{l}\text { Pengambilan sampel dilakukan dengan cara quota sampling. Analisis } \\
\text { menggunakan analisis regresi linier. Hasil penelitian menunjukkan bahwa terdapat }\end{array}$ \\
& pengaruh yang signifikan antara kasih sayang ibu terhadap kontraksi persalinan \\
& dengan kecemasan ibu dalam menjalani persalinan.
\end{tabular}

EFFECTIVENESS OF SAFE MOTHERHOOD TO LABOR CONTRACTION AND MOTHER'S ANXIETY IN SOUTH TANGERANG REGION HEALTH CENTER

Keywords:

Safe motherhood, labor

contractions, anxiety

\begin{abstract}
Many complications that cause maternal and infant death can be avoided if labor is managed properly. All childbirth must be handled by health workers who are trained and competent by quickly and accurately diagnosing and managing complications. When providing care, it is very important to remember that it is more likely that people will use good services by applying maternal care. Safe motherhood is a. mother's loving care that upbringing with the principle of mutual respect for the culture, beliefs and desires of the mother. One of the principles of loving mother's care is to include the husband and family during labor. The study design used observational analytic with a case control approach. The study population was maternity mothers who gave birth in South Tangerang regional health centers in June to October 2018. Samples were taken by quota sampling. The analysis used linear regression analysis. The results of the research showed that there was a significant effect between giving care to the mother's love for labor contractions and maternal anxiety in undergoing labor.
\end{abstract}

Korespondensi Penulis:

Sri Handayani

Jl. Wijaya Kusuma Raya No.47-48, Cilandak Jakarta Selatan

email :handayani.edi30@gmail.com 


\section{PENDAHULUAN}

Mortalitas dan Morbiditas pada wanita hamil dan bersalin merupakan masalah besar di negara berkembang. Persalinan merupakan suatu proses alami yang akan berlangsung dengan sendirinya, tetapi persalinan pada manusia setiap saat terancam penyulit yang membahayakan ibu maupun janinnya sehingga memerlukan pengawasan, pertolongan dan pelayanan dengan fasilitas yang memadai. Persalinan dibagi menjadi empat tahap penting dan kemungkinan penyulit dapat terjadi pada setiap tahap tersebut (Manuaba, 2010).

Banyak penyulit dan komplikasi yang menyebabkan kematian ibu dan bayi dapat dihindarkan jika persalinan dikelola dengan baik. Semua kelahiran harus ditangani oleh penolong yang terlatih serta kompeten dengan secara cepat dan tepat mendiagnosa dan menangani penyulit. Ketika memberikan asuhan, sangat penting diingat bahwa lebih besar kemungkinan orang akan menggunakan pelayanan yang baik dengan menerapkan asuhan sayang ibu (Pusdiknakes - WHO, 2010).

Ibu merupakan kesatuan dari Bio Psikososial Spiritual maka perlu perhatian khusus dari bidan yang dalam menyiapkan fisik dan mental guna meningkatkan serta mencegah komplikasi lebih lanjut. Semua wanita menginginkan bisa melahirkan secara normal. elahirkan secara normal artinya melahirkan secara pervaginam yaitu bayi lahir melalui jalan lahir dan dilakukan dengan tenaga ibu sendiri. Setiap wanita tentunya mengidamkan dapat melahirkan sendiri dan merasakan perasaan menjadi seorang ibu, yang rela mempertaruhkan nyawa untuk melahirkan buah hati yang amat ditunggu-tunggu kedatangannya (Sarwono Parwihardjo, 2012).

Beberapa penelitian menunjukkan bahwa banyak ibu bersalin yang masih tidak mau meminta pertolongan tenaga penolong terlatih untuk memberikan asuhan selama persalinan dan kelahiran bayi. Sebagaian dari mereka beralasan bahwa penolong persalinan terlatih tidak benar-benar memperhatikan kebutuhan atau kebudayaan, tradisi dan keinginan pribadi para ibu dalam persalinan dan nifas dan lainnya bahwa sebagian besar fasilitas kesehatan memiliki peraturan dan prosedur kurang bersahabat dan menakutkan bagi para ibu (Tambuwun, 2014).

Menurut Pusdinakes (2010) salah satu prinsip umum asuhan sayang ibu adalah menghargai hak-hak ibu dan memberikan asuhan yang baik, berkualitas serta sopan dan penuh kasih sayang(Pusdiknakes - WHO, 2010).

Safe motherhood adalah program yang direncanakan pemerintah untuk mengurangi tingginya angka kematian dan kesakitan para ibu yang diakibatkan oleh komplikasi kehamilan dan kelahiran. Asuhan sayang ibu adalah asuhan dengan prinsip saling menghargai budaya, kepercayaan dan keinginan ibu, Salah satu prinsip asuhan sayang ibu adalah dengan mengikutsertakan suami dan keluarga selama persalinan (Erawati A, 2011) . Asuhan persalinan adalah memberikan dukungan, baik fisik maupun emosional, melakukan pengkajian, membuat diagnosis, mencegah komplikasi, menangani komplikasi, melakukan rujukan pada kasus yang tidak dapat ditangani sendiri, memberikan asuhan yang adekuat kepada ibu dengan intervensi minimal sesuai dengan tahap persalinannya, memperkecil resiko infeksi, memberitahu ibu dan keluarganya mengenai kemajuan persalinan, memberikan asuhan yang tepat untuk bayi segera setelah lahir, membantu ibu dalam pemberian ASI dini (Asrinah, 2010).

\section{METODE}

Desain penelitian menggunakan observasional analitik dengan pendekatan case control dengan rancangan the only posttest with control group, Sampel diambil secara quota sampling sebanyak 30 responden yang melahirkan di Puskesmas Pondok Benda dan Puskesmas Benda Baru wilayah Tangerang Selatan. Instrumen penelitian menggunakan lembar observasi dan daftar tilik sedangkan untuk mengukur kecemasan ibu di ukur dengan skala HARS (Hamilton Anxiety Rating Rating Scale), terdapat 14 symptoms, setiap item yang diobservasi diberi 5 tingkatan skor antara 0 ( $\mathrm{Nol}$ Present) sampai dengan 4 (severe). Uji analisis menggunakan analisis regresi linier (Pusdiklat Nakes Kemenkes RI, 2015)

\section{HASIL}

Penelitian ini menggunakan data primer terhadap ibu bersalin. Observasi dilakukan selama proses persalinan berlangsung yang dimulainya dari kala I sampai dengan kala IV dengan pencatatan terhadap lamanya proses persalinan berlangsung. Saat proses persalinan 
pada kelompok intervensi dilakukan pemberian asuhan sayang ibu yang meliputi seluruh item yang terdapat pada lembar observasi.

Tabel.1 Distribusi Karakteristik Responden pada Kelompok Intervensi Dan Kelompok Kontrol

\begin{tabular}{|c|c|c|c|c|c|c|c|c|c|c|c|c|}
\hline \multirow[t]{2}{*}{ Variabel } & \multicolumn{6}{|c|}{ Kelompok Intervensi } & \multicolumn{6}{|c|}{ Kelompok Kontrol } \\
\hline & mean & $\min$ & $\max$ & SD & SE & n & mean & $\min$ & $\max$ & SD & SE & n \\
\hline umur ibu (tahun) & 29.6 & 20 & 41 & 5.94 & 0.63 & 30 & 29.2 & 20 & 41 & 6.37 & 0.83 & 30 \\
\hline Paritas & 2 & 1 & 5 & 1.26 & 0.13 & 30 & 2 & 1 & 5 & 1.32 & 0.17 & 30 \\
\hline \multirow[t]{2}{*}{ Variabel } & \multicolumn{4}{|c|}{ Kelompok Intervensi } & & & \multicolumn{4}{|c|}{ Kelompok Kontrol } & & \\
\hline & & $\mathrm{F}$ & & Prosentase & n & & f & & rosenta & n & & \\
\hline \multicolumn{13}{|l|}{ Pendidikan ibu: } \\
\hline Rendah & & 10 & & 33.3 & 30 & & 18 & & 60.0 & 30 & & \\
\hline Tinggi & & 20 & & 66.7 & & & 12 & & 40.0 & & & \\
\hline \multicolumn{13}{|l|}{ pekerjaan ibu: } \\
\hline Bekerja & & 16 & 6 & 53.3 & 30 & & 15 & & 50.0 & 30 & & \\
\hline Tidak bekerja & & 14 & & 46.7 & & & 15 & & 50.0 & & & \\
\hline
\end{tabular}

Tabel 1 menunjukkan bahwa usia responden pada kedua kelompok rata-rata pada kelompok kasus adalah 29,6 bulan dan kelompok kontrol 29,2 bulan. Kelompok paritas rata-rata terbanyak pada kelompok kasus maupun kelompok kontrol adalah 2 orang. Jenis Proporsi terbesar tingkat pendidikan responden pada kelompok intervensi yaitu pendidikan tinggi (SMA dan PT) sebanyak 66,7 \%, sedangkan pada kelompok kontrol terbesar pendidikan rendah (SD dan SMP) sebanyak $60,0 \%$. Proporsi terbesar untuk status pekerjaan pada kelompok intervensi adalah ibu bekerja sebanyak 53,3\%, sedangkan proporsi pada kelompok kontrol adalah sama yaitu sebesar $50 \%$.

Tabel 2 Pengaruh Asuhan Sayang terhadap Kontraksi Persalinan dan Kecemasan pada Kelompok Intervensi dan Kelompok Kontrol

\begin{tabular}{|c|c|c|c|c|c|c|c|c|}
\hline \multirow{2}{*}{ Variabel } & \multicolumn{4}{|c|}{ kelompok Intervensi } & \multicolumn{4}{|c|}{ Kelompok Kontrol } \\
\hline & mean & SD & $959 \mathrm{CI}$ & Pvalue & mean & SD & $9590 \mathrm{Cl}$ & Pvalue \\
\hline Kontrakssi Persal & 3.5 & 0.509 & $-2.195 \cdot(-1.672)$ & 0.0001 & 1.23 & 0.43 & $-21,195-(-1.672)$ & 0.0001 \\
\hline Kecemasan Ibu & 7.33 & 1,028 & $7.214 \cdot 10.253$ & 0.0001 & 17,07 & 0.980 & $17,423-20,356$ & 0.435 \\
\hline
\end{tabular}

Tabel 2 menunjukkan adanya perbedaan rata-rata lamanya kontraksi pada kelompok intervensi lebih sering terjadinya kontraksi yaitu 3,5 kali dalam sepuluh menit dengan $\mathrm{SD}=0,509$ (95\% $\mathrm{CI}=-2,195-(-1,672)$, sedangkan pada kedua kelompok diperoleh hasil $\mathrm{p}$ value $=0,001$, yang berarti bahwa pemberian asuhan sayang ibu berpengaruh terhadap pada kedua kelompok. Pada tingkat kecemasan ibu setelah pemberian asuhan sayang ibu rata-rata skor pada kelompok intervensi lebih rendah dibandingkan kelompok kontrol yaitu 7,33 (tingkat kecemasan ringan) dengan nilai SD $=1,028(95 \% \mathrm{CI}=7,214-10,253)$, dengan nilai $\mathrm{p}$ value $=0,0001$ berarti pemberian asuhan sayang ibu berpengaruh terhadap kecemasan ibu selama persalinan berlangsung,

Tabel 3 Seleksi Bivariat Variabel-variabel Yang Lolos/Masuk Pemodelan Analisis Multivariat

\begin{tabular}{l|cc|c}
\hline Variabel & Uji Statistik & P value & Seleksi \\
\hline Umur ibu & Korelasi & 0,0001 & Lolos \\
\hline Pendidikan ibu & T-test Independen & 0,194 & Lolos \\
\hline Pekerjaan Ibu & T-test Independen & 0,16 & Lolos \\
\hline Paritas & Korelasi & 0,0001 & Lolos \\
\hline
\end{tabular}

Tabel 4 Model Akhir. Analisis Regresi Linier Pemberian Asuhan Sayang Ibu Terhadap Lamanya

\begin{tabular}{c|c|c|c|c}
\multicolumn{5}{c}{ Persalinan } \\
\hline Variabel & P value & Coefficients & \multirow{2}{*}{ R Square } & Constanta \\
\hline Pemberian Asuhan Say ang lbu & 0,0001 & $-1,944$ & & \\
\cline { 1 - 3 } His (kontraksi) & 0,003 & 0,625 & \multirow{2}{*}{0,671} & \multirow{2}{*}{8,113} \\
\cline { 1 - 3 } Tingkat Kecemasan & 0,009 & $-0,825$ & & \\
\hline
\end{tabular}

Dari tabel diatas, dapat diketahui variabel pemberian asuhan sayang ibu bermakna terhadap lamanya persalinan dengan nilai $\mathrm{P}$ value $=0,0001$. Dipderoleh Coefficient determinasi $R^{2}(\mathrm{R}$ square $)=0,671$, artinya variabel pemberian asuhan sayang ibu dapat menjelaskan variasi lamanya persalinan sebesar $67,1 \%$ dan sisanya dijelaskan oleh variabel lain. Nilai $\mathrm{P}$ value (prob $>\mathrm{F})=0,0001$ berarti persamaan garis regresi secara keseluruhan signifikan.

Adanya perbedaan terjadinya kontraksi persalinan setelah diberikan asuhan sayang ibu dapat meningkatkan kontraksi persalinan sebesar 0,625 kali dan tingkat skor kecemasan ibu akan berkurang sebesar 0,825. Asuhan kebidanan yang diberikan, hendaknya asuhan yang sayang ibu dan bayi. Asuhan yang sayang ibu ini akan memberikan perasaan aman dan nyaman selama persalinan dan kelahiran. Hal ini sejalan dengan penelitian yang dilakukan oleh Herly KT, dkk (2014), dengan hasil penelitian diperoleh bahwa ibu-ibu bersalin yang dilakukan asuhan sayang ibu 
sebagian besar persalinannya normal yaitu sebesar $58 \%$.

\section{PEMBAHASAN}

\section{A. Distribusi Karakteristik Ibu Terhadap Lamanya Persalinan}

Dari hasil penelitian diperoleh hasil bahwa usia responden pada kedua kelompok rata-rata pada kelompok kasus adalah 29,6 bulan dan kelompok kontrol 29,2 bulan. Kelompok paritas rata-rata terbanyak pada kelompok kasus maupun kelompok kontrol adalah 2 orang. Jenis Proporsi terbesar tingkat pendidikan responden pada kelompok intervensi yaitu pendidikan tinggi (SMA dan PT) sebanyak 66,7 \%, sedangkan pada kelompok kontrol terbesar pendidikan rendah ( SD dan SMP) sebanyak 60,0\%. Proporsi terbesar untuk status pekerjaan pada kelompok intervensi adalah ibu bekerja sebanyak 53,3\%, sedangkan proporsi pada kelompok kontrol adalah sama yaitu sebesar 50\% .

Persalinan merupakan suatu proses alami yang akan berlangsung dengan sendirinya, tetapi persalinan pada manusia setiap saat terancam penyulit yang membahayakan ibu maupun janinnya sehingga memerlukan pengawasan, pertolongan dan pelayanan dengan fasilitas yang memadai. Ibu merupakan kesatuan dari Bio Psikososial Spiritual maka perlu perhatian khusus dari bidan yang dalam menyiapkan fisik dan mental guna meningkatkan serta mencegah komplikasi lebih lanjut (Asrinah, 2010).

Semua wanita menginginkan bisa melahirkan secara normal. Ini merupakan proses alami, namun agar semua berjalan dengan lancar tanpa penyulit apapun, maka diperlukan sebuah persiapan (Helen Varney, 2006). Secara psikologis wanita hamil merasa takut tentang hal yang sudah jelas ataupun belum jelas tentang persalinan, sehingga menimbulkan perasaan bahwa nantinya tidak akan mampu mengatasi masalah, diantaranya adalah apa yang harus dilakukan saat persalinan, cara mengatasi rasa nyeri pada saat kontraksi, ketegangan, serta diperlukannya dukungan moril dari penolong persalinan (physician) sehingga wanita hamil merasa aman dan nyaman.(Sarwono Parwihardjo, 2012)

\section{B. Pemberian Asuhan Sayang Ibu Terhadap Kontraksi Persalinan dan Kecemasan Ibu Dari hasil uji satatistik dapat diketahui}

bahwa variabel pemberian asuhan sayang ibu bermakna terhadap kontraksi persalinan dengan nilai $P$ value $=0,0001$. Dengan nilai Coefficient determinasi $R^{2}(R$ square $)=0,671$, artinya variabel pemberian asuhan sayang ibu dapat menjelaskan variasi kontraksi persalinan sebesar $67,1 \%$ dan sisanya dijelaskan oleh variabel lain. Pemberian asuhan sayang ibu dapat meningkatkan kontraksi persalinan sebesar 0,625 kali setelah dikontrol dengan variabel pemberian asuhan sayang ibu dan tingkat kecemasan.Tingkat skor kecemasan ibu akan berkurang sebesar 0,825 pada ibu yang diberikan asuhan saying ibu setelah dikontrol dengan variabel pemberian asuhan sayang ibu dan kontraksi persalinan.

Beberapa penelitian (Pramitasari, Umah, \& Qomar, 2010) menunjukkan bahwa banyak ibu bersalin yang masih tidak mau meminta pertolongan tenaga penolong terlatih untuk memberikan asuhan selama persalinan dan kelahiran bayi. Sebagaian dari mereka beralasan bahwa penolong persalinan terlatih tidak benar-benar memperhatikan kebutuhan atau kebudayaan, tradisi dan keinginan pribadi para ibu dalam persalinan dan nifas dan lainnya bahwa sebagian besar fasilitas kesehatan memiliki peraturan dan prosedur kurang bersahabat dan menakutkan bagi para ibu. Menurut Pusdinakes (2010) salah satu prinsip umum asuhan sayang ibu adalah menghargai hak-hak ibu dan memberikan asuhan yang baik, berkualitas serta sopan dan penuh kasih sayang (Pusdiknakes - WHO, 2010).

Asuhan sayang ibu atau safe motherhood adalah program yang direncanakan pemerintah untuk mengurangi tingginya angka kematian dan kesakitan para ibu yang diakibatkan oleh komplikasi kehamilan dan kelahiran. Asuhan sayang ibu adalah asuhan dengan prinsip saling menghargai budaya, kepercayaan dan keinginan ibu, Salah satu prinsip asuhan sayang ibu adalah dengan mengikutsertakan suami dan keluarga selama persalinan (Soviyati, 2016).

Asuhan persalinan adalah memberikan dukungan, baik fisik maupun emosional, melakukan pengkajian, membuat diagnosis, mencegah komplikasi, menangani komplikasi, melakukan rujukan pada kasus yang tidak dapat ditangani sendiri, memberikan asuhan yang adekuat kepada ibu dengan intervensi minimal sesuai dengan tahap persalinannya, memperkecil resiko infeksi, memberitahu ibu dan keluarganya mengenai kemajuan persalinan, memberikan asuhan yang tepat 
untuk bayi segera setelah lahir, membantu ibu dalam pemberian ASI dini.

Kebutuhan dasar selama persalinan tidak terlepas dengan asuhan yang diberikan bidan. Asuhan kebidanan yang diberikan, hendaknya asuhan yang sayang ibu dan bayi. Asuhan yang sayang ibu ini akan memberikan perasaan aman dan nyaman selama persalinan dan kelahiran (Asri H, 2010). Hal ini sejalan dengan penelitian yang dilakukan oleh Herly KT, dkk (2014), dengan hasil penelitian diperoleh bahwa ibu-ibu bersalin yang dilakukan asuhan sayang ibu sebagian besar persalinannya normal yaitu sebesar 58\% (Fallis, 2013).

Hasil analisis pemberian asuhan sayang ibu dalam hal ini sangat membantu ibu untuk rileks dan dapat meringankan sakit atau his yang dirasakan ibu selama proses persalinan, dan dukungan emosional yaitu tingkat kecemasan yang sedikit, dan pemberian penjelasan pada setiap tindakan yang akan dilakukan, dapat mempercepat lamannya proses persalinan.

\section{KESIMPULAN}

Hasil analisis pemberian asuhan sayang ibu sangat berpengaruh terhadap proses persalinan yang sangat membantu ibu untuk rileks dan dapat meningkatkan kontraksi atau his ibu selama proses persalinan, dan menurunkan tingkat kecemasan ibu dalam menghadapi persalinan, sehingga dapat mempercepat lamannya proses persalinan. Penelitian ini merekomendasikan bagi ibu yang akan melahirkan sebaiknya diberikan asuhan sayang ibu secara maksimal dan tepat sehingga ibu merasakan keyamanan dan tenang.

\section{DAFTAR PUSTAKA}

Asri H. (2010). Asuhan Persalinan Normal. (Cetakan pe). Yogjakarta: Nuha Medika.

Asrinah, dkk. (2010). Asuhan Kebidanan Masa Persalinan. Yogjakarta: Graha Ilmu.

Erawati A. (2011). Buku ajar asuhan kebidanan persalinan normal (2nd ed.). JAKARTA: EGC.

Fallis, A. . (2013). Hubungan asuhan sayang ibu dengan kecemasan. Journal of Chemical Information and Modeling, 53(9), 16891699.

https://doi.org/10.1017/CBO9781107415 324.004

Helen Varney. (2006). Buku Ajar Asuhan
Kebidanan. JAKARTA: EGC.

Manuaba, B. I. G. (2010). Buku Ajar Keperawatan Maternitas dan Ginekologi. In Keperawatan. JAKARTA: EGC.

Pramitasari, A., Umah, B., \& Qomar, U. (2010). Penerapan Asuhan Sayang Ibu Selama Proses Persalinan di Bidan Wilayah Puskesmas Gombong I dan Gombong II. Keperawatan, 6(3), 118-126.

Pusdiklat Nakes Kemenkes RI. (2015). Kurikulum dan Modul Pelatihan Metodologi Penelitian Bagi Tenaga Pendidik. JAKARTA: Pusdiknakes.

Pusdiknakes - WHO. (2010). Asuhan Intrapartum. JAKARTA: JHPIEGO.

Sarwono Parwihardjo. (2012). Ilmu Kebidanan. JAKARTA: EGC.

Soviyati, E. (2016). Faktor-Faktor Yang Berhubungan Dengan Lama Persalinan Di Rsud'45 Kuningan Jawa Barat Tahun 2015. Jurnal Bidan "Midwife Journal," 2(1), 33-43.

Tambuwun, H. K. (2014). Hubungan Pelaksanaan Asuhan Sayang Ibu Dengan Lamanya Persalinan. Jurnal Ilmiah Bidan, 2(1), 1-9. 